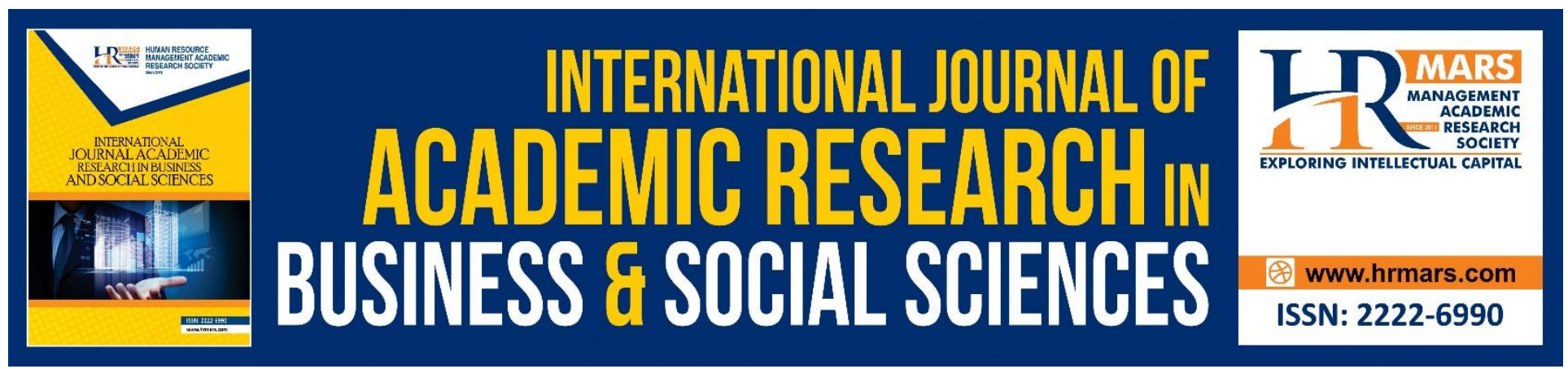

\title{
Knowledge Management and Job Satisfaction
}

\author{
Farah Nadiah Tajul Arif, Safawi Abdul Rahman
}

To Link this Article: http://dx.doi.org/10.6007/IJARBSS/v8-i9/4589

DOI: $\quad 10.6007 /$ IJARBSS/v8-i9/4589

Received: 17 August 2018, Revised: 27 September 2018, Accepted: 29 September 2018

Published Online: 13 October 2018

In-Text Citation: (Arif \& Rahman, 2018)

To Cite this Article: Arif, F. N. T., \& Rahman, S. A. (2018). Knowledge Management and Job Satisfaction. International Journal of Academic Research in Business and Social Sciences, 8(9), 266-274.

\section{Copyright: (C) 2018 The Author(s)}

Published by Human Resource Management Academic Research Society (www.hrmars.com)

This article is published under the Creative Commons Attribution (CC BY 4.0) license. Anyone may reproduce, distribute, translate and create derivative works of this article (for both commercial and non-commercial purposes), subject to full attribution to the original publication and authors. The full terms of this license may be seen at: http://creativecommons.org/licences/by/4.0/legalcode

Vol. 8, No. 9, September 2018, Pg. 266 - 274

Full Terms \& Conditions of access and use can be found at http://hrmars.com/index.php/pages/detail/publication-ethics 


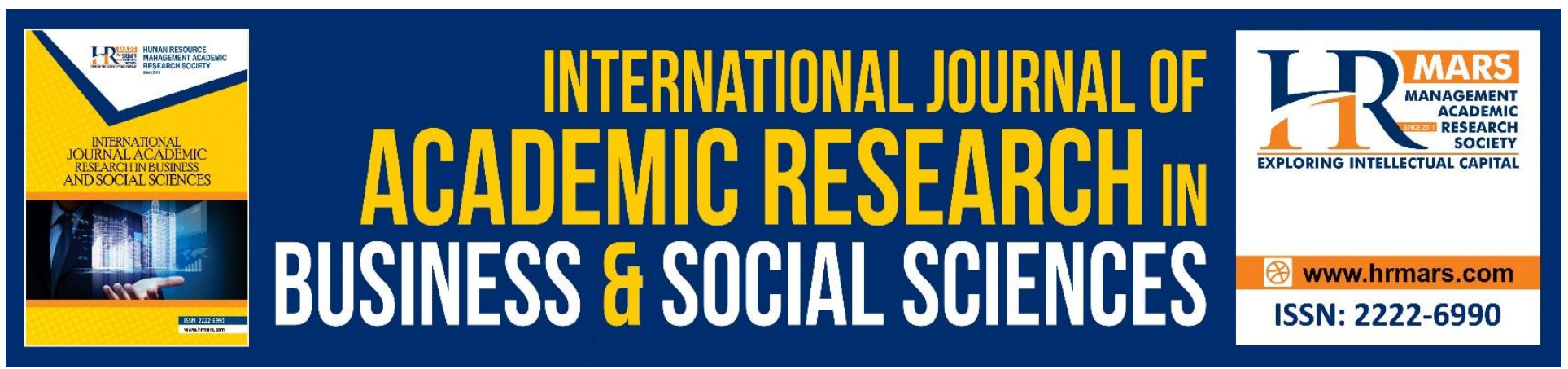

\title{
Knowledge Management and Job Satisfaction
}

\author{
Farah Nadiah Tajul Arif \\ Post Graduate Student, Faculty of Information Management, Universiti Teknologi MARA (Selangor) \\ Puncak Perdana Campus, UiTM Selangor, 40150 Shah Alam, Selangor. \\ Email: farahnadiah93@gmail.com
}

\section{Safawi Abdul Rahman}

Senior Lecturer, Faculty of Information Management, Universiti Teknologi MARA (Selangor) Puncak Perdana Campus, UiTM Selangor, 40150 Shah Alam, Selangor.

Email: safawi@salam.uitm.edu.my

\begin{abstract}
Knowledge management is a tool that includes human, processes and technology for managing information and knowledge resources in an organization. With its variety of benefits, job satisfaction appears within the knowledge management process in industries. This paper reviews the relationship of knowledge management with job satisfaction concentrate on healthcare in Malaysia. Numerous organizations such as business, banking, telecommunications as well healthcare which is focus on had knowledge management relevance. Using the scoping review technique, a number of scholarly articles on knowledge management related subjects and job satisfaction in different industries have been gathered and reviewed. The majority analysis of the retrieved articles found that knowledge management positively correlate with job satisfaction. It is also identified that knowledge management are crucial in every industry that being discussed.
\end{abstract}

Keywords: Information Management, Knowledge Management, Job Satisfaction

\section{Introduction}

Knowledge and knowledge management are universal subjects of interest and they have been defined and interpreted differently by scholars from previous days and civilizations. According to the Oxford English Dictionary (2018), knowledge is know-how and skills obtained by a person all through experience or education as well the theoretical or practical understanding of a subject. Alavi and Leidner (2001) in their paper described knowledge management (KM) is where systematic and organized attempts in using organization inner knowledge assets to improve performance. In general,

$\mathrm{KM}$ is continually stays in every persons' minds.

In any organization, $\mathrm{KM}$ is able facilitate the employees in conducting their daily routines. RingelBickelmaier \& Ringel (2010) mentioned that knowledge usage is one of major significance for the daily work of international organizations' staffs. KM is needed as high consumption and a high 
INTERNATIONAL JOURNAL OF ACADEMIC RESEARCH IN BUSINESS AND SOCIAL SCIENCES Vol. 8, No. 9, Sept. 2018, E-ISSN: 2222-6990 @ 2018 HRMARS

production of information are common characters of international organizations. Fernandez and Sabherwal (2010) stated knowledge is one of most crucial assets as workers' job routines became set in the mind of the person that gained through experiences, skills and intelligence of the employees. Managing organizational and staffs' daily tasks, KM would be an important tool to be considered.

Job satisfaction is a subject that measure employee level of acceptance and patience when they are doing their work routines. Glick (1992) indicated that satisfaction is an in-effect response by individuals be caused by appraisal of their work roles in the job that they currently conduct. Uzonna (2013) expressed that pleased workers be an effect of gaining a sense of achievement and personal acknowledgement from top management. Consequently, Javed, Balouch, and Hassan (2014) insinuated that job satisfaction in lower level will leave a bad impact on the organization, whereas a higher level of satisfaction will produce a positive outcome in the organization. Level of satisfaction need to take notice in succession to ensure the smooth performance in organization.

KM is believed to have relationship with job satisfaction. In a study by Lee and Chang (2007), the correlation between staff's job satisfaction and KM in Taiwan is the studied subject. In the same way, positive relationship of KM and employee job satisfaction can be view in research conducted by Singh and Sharma (2011) that comprise telecommunication industries in India. Likewise, Almahamid et al. (2010) stress on the influences of knowledge sharing with 160 Jordan staffs' job satisfaction shows significantly relation. Knowledge management and job satisfaction are assessed to be correlate and influencing each other.

The objective of this paper is to present the review on the practice of knowledge management and job satisfaction in healthcare industry. In presenting the review, this paper arranged as follow. The next section briefly reviews the knowledge management, job satisfaction and relationship between knowledge management and job satisfaction. Some theoretical foundation pertaining to knowledge acquisition, knowledge sharing, knowledge creation, knowledge codification, knowledge retention and job satisfaction is discussed. The methodology that this paper was used is discussion in next coming sections. Some brief explanation is broad forward in to response the presented literature. The conclusion of the review is offended.

\section{Literature Review}

The literature review considers significant to suggest and bring out ideas as well knowledge for researchers. In this literature review, different parts from various papers will be discussed and explain. The review is divided into 4 distinct components as below.

\section{Knowledge and Knowledge Management}

The term knowledge management is much more complicated than the terms management and knowledge. Nonaka (1994) put forward organizational knowledge creation theory in tacit knowledge is believed to be a fundamental and major concern. Indeed, she also stated that KM processes should be utilized in putting knowledge activities into practices. This is to ensure the efficiency of knowledge flow with the purpose of transforming implicit or tacit knowledge into explicit knowledge.

Knowledge is an important asset that need to preserve in every workplaces. Based on opinions of Maruf and Zhou (2015), knowledge is one of the treasured assets that need to take into consideration 
in these days' organizations. This is due to it turn out to be one of the most vital production factors with the workforce and the funds. In addition, it is the main mechanism for the growing of economy and the facilitator for technology expansion and production enrichment. Thus, the innovation and its transforms into processes and products is set up by knowledge. Davenport (1996) has uttered knowledge as a fluid mix of enclosed know-how, values, appropriate information, and expert comprehension that responsible for a framework as for evaluating and assimilating latest experiences and information. Knowledge in workers need to be preserved to avoid organizational amnesia or losing of knowledge.

Knowledge can be explained as whether tangible or intangible that can be stated as explicit or tacit. At the very first, Polanyi (1966) divided human knowledge into two elements which are explicit knowledge and tacit knowledge. Explicit knowledge is much more written in a formal way, data conveyed, formulary scientific, arrangements, instruction manual, or textbooks. Meanwhile, tacit knowledge is usually action based and unclear, vastly personal and difficult to pass on. He indicated that knowledge is not obtained by the number of experiences and made known efforts. On the contrary, it comes from the circumstances of human being such as the feel of beauty and enthusiasm (Polanyi, 1962, 1966). Explicit knowledge and tacit knowledge supplement each other's in supporting organization personnel to give out a good job performance.

Application of knowledge entails positioning the organization's setting to achieve the highest benefit. Taylor et. al (1996) described knowledge management (KM) as the process of significantly managing knowledge to gather existing needs, to identify and make the most of existing and acquired knowledge assets and to take on new opportunities. Correspondingly, to manage leadership, KM requires an excellent pattern in leadership where it emphases on honesty, joint trust and exchange of ideas with others to reach the top level of productivity in the organization. Information technology aspirations to cater advanced business network, data bases, tools and software that smooth the progress of the KM in the organization, as well to the most apposite organizational formations for $\mathrm{KM}$ that is flexible and adoptable, simple to communicate, and has a fast response to changes by adopting the horizontal organizational structure (Ababneh and Hatamleh, 2013; Lopez et al., 2004).

\section{Knowledge Management in Industries}

Knowledge management are broadly implemented in different in several industries or fields. In this section various implementation of KM in business, banking and telecommunications industries are exemplified.

\section{Business}

Critical resource is knowledge itself in business arena. As reported by McFayden and Canella (2004) knowledge is a necessity element for enterprises to solve problems concerning functioning as well meet decisions to aid strategies in business. In addition, Galandere-Zile and Vinogradova (2005) justified that knowledge in the business perspective was reflected a form of actionable information. $\mathrm{Gao}$, Li, and Clarke (2008) said in business with the purpose of implement knowledge management, their objectives need to be clear. In this manner, companies produce, exchange words, and control their intellectual assets. They also said that knowledge management in a business organization implies in managing activities of knowledge workers. Those activities earned through enabling, encouraging, controlling, and hold up knowledge workers and raising a suitable working atmosphere. For this reason, it can be declared that KM in business industries are usual among their staffs. 


\section{Banking}

Similar to business sector, knowledge and knowledge management is a major factor of effective performance in banking industry. Silver and Berggren (2010) indicated that knowledge regarded as the contributing factor of quality service performance mainly after banking products are close to perceived as similar to one another. In conjunction with Cham, Lim, Cheng, \& Lee (2016), where their research is executed to determine the successful factors of knowledge management systems (KMS) in the banking industry. It stated that both technical and social stand point in analyzing how KMS can be successful. The social factors on KMS success' models was raised. Results from this study proved that a consistently type of KMS can boost workers' satisfaction and sustain competitive advantage at the same time on behalf of any organizations that implemented the system. Hence, the process of put up and keep up an effective KMS deliberately has become a crucial part of the banking organization.

\section{Telecommunication}

Telecommunications industries have to make use of KM in the direction of gain advantages to keep standing competitive. Gorelik (2003) concluded that knowledge is one of important resource in lessening hesitations and the only maintainable basis of competitive advantage to these telecommunication organizations. Yusof (1998) expressed that telecommunication industry expand into differentiated functions along with the era of industrial development and information age. He also added, that it is aimed to support the expansion of technological advancement for improved services demanded by everyone. As stated by Singh and Sharma, (2011) their research is possibly the first to analytically determine the antecedents of KM implementation in the Telecom sector in India. The survey medium containing character of organizational culture, diagnostics of organizational learning, KM placement and employee satisfaction. There is a positive affiliation disclosed in all proposed elements. Thus, KM in telecommunication mainly give good vibe in their business process.

\section{Job Satisfaction}

Job satisfaction is to measure on how content a worker in doing their job every day. As stated by Spector (1994), he defined job satisfaction as the level to which people like (satisfaction) or dislike (dissatisfaction) their jobs. Shaikh et al. (2012) described job satisfaction where the personnel takes contentment from their work, or the positive and emotional state of the employee after appraisal of his or her job and performance. Hence, job satisfaction should be fulfilled with contentment to ensure work productivity.

Although it is important to satisfy customers, employees satisfaction is also very important. Despite the fact, Hoffman and Ingram (1992) discovered that employees satisfaction need to be fulfilled first before satisfying the customers' needs. Moreover, it shown that the most important workers' overall job satisfaction is positively linked with their customer-oriented manners. Furthermore, Rogers et al. (1994) highlight that service employees who often mingle with customers will face difficult time when they are not happy and dissatisfied about some aspect of their job. This is supported by Karl and Peluchette (2006) who said staffs build satisfied customers simultaneously. This is sustained that happy workers bring in more happy clients. 
INTERNATIONAL JOURNAL OF ACADEMIC RESEARCH IN BUSINESS AND SOCIAL SCIENCES

Vol. 8, No. 9, Sept. 2018, E-ISSN: 2222-6990 @ 2018 HRMARS

There are few issues on what causing workers to become dissatisfied. Nordheimer (1994) defined that in a casino work setting, stress regarding the job normally be caused by several problems. Those related difficulties are mostly happened when they continuously switching their scheduled shifts along with players and surveillance cameras that always keep an eye on them while working. Hence, he suggested that trim down job stress is a significant part of job satisfaction for casino workers.

Motivation and satisfaction correlate with each one. Herzberg $(1959,1966)$ has carried out studies on job satisfaction of workers in a variation of sites. His Motivation Hygiene Theory which are twofactor approach, declared that there are components within the job and job environment which affect satisfaction or lack of satisfaction in different persons. His principle is that the intrinsic factors, or job content, lead to worker satisfaction, and there are extrinsic factors, or job surroundings, which decrease satisfaction. The motivation factors are itemized as satisfiers, due to reason they encourage us to achieve a better performance on doing job. In contrast, the hygiene factors are called dissatisfiers which it precludes us from give out best performance.

\section{Knowledge Management and Job Satisfaction}

According to (Kianto, Vanhala, \& Heilmann, 2016) titled The impact of knowledge management on job satisfaction which aims to examine how KM can improve staff job satisfaction in person. The studied KM facets consist of knowledge acquisition, knowledge sharing, knowledge creation, knowledge codification and knowledge retention and their relationship to job satisfaction. The sample of the study was tested empirically by analyzing a web-based survey data set of 824 individuals which collected from the workers of a Finnish municipal organizations including administration, social and health services, education and culture, work, entrepreneurships and business services and technical and environmental services. The authors also differentiate the groups of employees such as general employees, experts, middle managers and top management.

In Kianto, Vanhala, \& Heilmann (2016) study, it was found that three KM facets which are knowledge sharing, codification and retention showed positive relationships with job satisfaction. The results indicated that internal knowledge sharing is the fundamental of KM process whereas it promote job satisfaction nearly for all employee groups. Mutual support and encouragement, and a positive work climate, seem to be strong enablers of job satisfaction as well as high job performance. However, other two facets which are knowledge acquisition and knowledge creation do not affect job satisfaction at all. The authors predicted that public organization requires no more knowledge acquisition when it come from outside resources or associates. The new knowledge creation also faces the same circumstances. It stated that those activities are not encouraged by both support or reward in the organization. As a result, they have no effect on job satisfaction.

\section{Methodology}

In establishing this paper, the approach of scoping was adopted. Following this approach, about thirty (30) articles on knowledge management and job satisfaction related subjects have been reviewed. All these articles were obtained or gathered from the Mendeley academic literature, journals from Google Scholar and various online databases subscribed by Library of University Teknologi MARA. Some selected keyword such as "information management", "knowledge" "knowledge management", "knowledge management in business", "knowledge management in banking", 
INTERNATIONAL JOURNAL OF ACADEMIC RESEARCH IN BUSINESS AND SOCIAL SCIENCES

Vol. 8, No. 9, Sept. 2018, E-ISSN: 2222-6990 @ 2018 HRMARS

"knowledge management in telecommunication" and "job satisfaction" have been used for searching or retrieving the relevant article.

\section{Discussion}

The result of review effort is divided into two items, namely the applicability of KM within functional department in healthcare sector and the influence of KM on job satisfaction.

\section{The Applicability of KM within Functional Department in Healthcare Sector}

There are many reasons for adopting the better knowledge management practices in healthcare, like patient wellbeing, supporting care and cutting treatment cost are the reasons to adopt knowledge management. Knowledge management is well known in any organizations that are in an office setting. But compare to healthcare such as hospitals and clinics, knowledge management seems being abandoned and ignored. According to Van Beveren (2003) study, he stated healthcare organizations expressly the public sectors ones are peculiar breed as they are not profit driven and funded mainly by the government. Indeed, in his interpretations, they are concerned by various issues to regard to cost, quality, efficiency and effectiveness of their healthcare which differentiates them with private healthcare sectors.

Healthcare facilities are considered as knowledge intensive organizations where this industry sharing of both tacit knowledge such as technical, expertise and experiential as well explicit knowledge which is documented records that are needed for quality healthcare delivery (Saeed, 2009). Dwivedi et al. (2006) identified that knowledge management as a concept in healthcare is totally new and much research has not been conducted to guide related academic and organizational stakeholders. Likewise, there is not much research on Knowledge Management (KM) being done in healthcare organizations specially in Malaysia. In many government organizations in Malaysia, there is no designated Knowledge Management Department, the task of implementing Knowledge Management activities is usually carried out by the Training Department.

\section{The Influence of KM on Job Satisfaction}

Knowledge management and job satisfaction showing positive linkages in numerous studies stated in literature review. As in Singh and Sharma, (2011), it displayed that Organizational Learning (OL) and knowledge management (KM) as well between Organizational Culture (OC) and KM where enhances employee satisfaction (ES) in their study. Oppositely, in Koseoglu et al. (2010) paper, they were failed to find a connection between KM and job satisfaction among 154 employees in one of luxury hotel in Turkey. They researched KM elements which were knowledge sharing and knowledge transfer. Overall, it can be expressed that current research verification on the relationship of KM and job satisfaction is rather lacking and limited. Besides that, KM studies always being relate with job performances while motivation always associate with job satisfaction.

\section{Conclusion}

In conclusion, knowledge management and job satisfaction are a link up with each other's. Various studies had proved that knowledge management in different organizations influence their staffs' job satisfaction. In this paper, the relationship between knowledge management and job satisfaction in industries has been presented. Though, there is some negative correlation found in certain KM facets with job satisfaction. The paper concludes that more future studies need to run so that more theories 
INTERNATIONAL JOURNAL OF ACADEMIC RESEARCH IN BUSINESS AND SOCIAL SCIENCES

Vol. 8, No. 9, Sept. 2018, E-ISSN: 2222-6990 @ 2018 HRMARS

and predictions can be accurately proven. In general, KM does provide advantages for any type of organizations along towards employees' satisfaction.

\section{References}

Ababneh, R., \& Hatamleh, M. (2013). The Role of organizational culture in supporting knowledge management in public hospitals in Jordan. JJBA, 9(4), 651.

Abualoush, S. H., Obeidat, A. M., Tarhini, A., Masa'deh, R. E., \& Al-Badi, A. (2018). The role of employees' empowerment as an intermediary variable between knowledge management and information systems on employees' performance. VINE Journal of Information and Knowledge Management Systems, 48(2), 217-237.

Alavi, M., \& Leidner, D. E. (2001). Knowledge management and knowledge management systems: Conceptual foundations and research issues. MIS quarterly, 107-136.

Berggren, B., \& Silver, L. (2010). Financing entrepreneurship in different regions: The failure to decentralise financing to regional centres in Sweden. Journal of Small Business and Enterprise Development, 17(2), 230-246.

Cham, T. H., Lim, Y. M., Cheng, B. L., \& Lee, T. H. (2016). Determinants of knowledge management systems success in the banking industry. VINE Journal of Information and Knowledge Management Systems, 46(1), 2-20. https://doi.org/10.1108/VJIKMS-03-2014-0021

Davenport, T. \& Prusak, L. (1998). Working knowledge: how organizations manage whatthey know. Harvard Business School Press, Boston, MA.

Dwivedi, A. N., Bali, R. K., \& Naguib, R. N. G. (2003, September). Organization current knowledge design (OCKD): A knowledge management framework for healthcare institutions. In Engineering in Medicine and Biology Society, 2003. Proceedings of the 25th Annual International Conference of the IEEE (Vol. 2, pp. 1236-1239). IEEE.

Dwivedi, Y. K., Choudrie, J., \& Brinkman, W. P. (2006). Development of a survey instrument to examine consumer adoption of broadband. Industrial Management \& Data Systems, 106(5), 700-718.

Ewen, R. B., Smith, P. C., \& Hulin, C. L. (1966). An empirical test of the Herzberg two-factor theory. Journal of Applied Psychology, 50(6), 544.

Galandere-Zile, I., \& Vinogradova, V. (2005). Where is the border between an information system and a knowledge management system? Managing Global Transitions, 3(2),179-196.

Gao, F., Li, M., \& Clarke, S. (2008). Knowledge, management, and knowledge management in business operations. Journal of Knowledge Management, 12(2), 3-17. https://doi.org/10.1108/13673270810859479

Gorelik, A. V. (2003). Knowledge process in Ukrainian organizations: The top performers of the machine building industry.

Hasan, M., \& Zhou, S. N. (2015). Knowledge Management in Global Organisations. International Business Research, 8(6), 165.

Herzberg, F. M., \& Mausner, B. (1959). B. and Snyderman, BB (1959) The motivation to work. Aufl., NewYork-London.

Herzberg, F. (2005). Motivation-hygiene theory. Organizational behavior one: Essential theories of motivation and leadership, eds JB Miner, ME Sharpe Inc, New York, 61-74.

Hoffman, K. D., \& Ingram, T. N. (1992). Service provider job satisfaction and customer. Journal of Services Marketing, 6(2), 68-78. 
INTERNATIONAL JOURNAL OF ACADEMIC RESEARCH IN BUSINESS AND SOCIAL SCIENCES

Vol. 8, No. 9, Sept. 2018, E-ISSN: 2222-6990 @ 2018 HRMARS

Karl, K., \& Peluchette, J. (2006). How does workplace fun impact employee perceptions of customer service quality? Journal of Leadership \& Organizational Studies, 13(2), 2-13.

Kianto, A., Vanhala, M., \& Heilmann, P. (2016). The impact of knowledge management on job satisfaction. Journal of Knowledge Management, 20(4), 621-636. https://doi.org/10.1108/JKM-10-2015-0398

Koseoglu, M., Bektas, C., Parnell, J. and Carraher, S. (2010). Knowledge management, organizational communication and job satisfaction: an empirical test of a five-star hotel in Turkey. International Journal of Leisure and Tourism Marketing, 1(4), 323-343.

Lianzhong, R. (2002). Merging knowledge management into hospital information system. Hospital Administration Journal of chinese PLA, 18(4), 238-240.

Marshall, J., \& Rossett, A. (2000). Knowledge management for school-based educators. In Integrated and Holistic Perspectives on Learning, Instruction and Technology (pp. 19-34). Springer, Dordrecht.

McFayden, A., \& Canella, A. (2004). Social capital and knowledge creation: Diminishing returns of the numbers and strength of exchange relationship. The Academy of Management Journal, 47(5), 35-37.

Mirza, R. S. (2009). Knowledge management and clinical framework for cross country healthcare organizations. Master, Department of Interaction and System Design, Blekinge Institute of Technology, Sweden.

Ringel-Bickelmaier, C., \& Ringel, M. (2010). Knowledge Management in International Organisations. Journal of Knowledge Management, 14(4), 524-539. https://doi.org/10.1108/13673271011059509

Singh, A. K., \& Sharma, V. (2011). Knowledge management antecedents and its impact on employee satisfaction. The Learning Organization, 18(2), 115-130. https://doi.org/10.1108/09696471111103722

Spector, P. (1994), Job Satisfaction Survey, University of South Florida, Tampa, FL.

Taylor et al. (1997). International Journal of Technology Management, 11(3), 385-91.

Van Beveren, J. (2003). Does health care for knowledge management? Journal of Knowledge Management, 7(1), 90-95.

Yingjun, T., Lei, Y., \& Bo, Y. (2002). Status quo and countermeasure of hospital knowledge management. Hospital Administration Journal of Chinese PLA, 9(5), 446-447.

Yusof, A. M. (1998). The future path of Malaysian telecommunication industry. Retrieved March, 13, 2007. 